\title{
Soluble tannins in plum fruit (Prunus domestica L.)
}

\author{
M. Vosnjak, M. Persic, R. Veberic and V. Usenik \\ University of Ljubljana, Biotechnical Faculty, Department of Agronomy, Chair for Fruit, Viticulture and Vegetable Growing, \\ Ljubljana, Slovenia
}

\begin{abstract}
Summary
Intensive breeding of European plum (Prunus domestica L.) for resistance against various diseases, especially sharka virus, has resulted also in cultivars with an astringent taste. Astringency is a known consequence of the presence of soluble tannins. The aim of the present study was to determine the content of total soluble tannins in flesh and peel of fruit of three plum cultivars ('Pozna plava', 'Plumtastic', 'Jojo'), and three maturity classes. Total insoluble phenolic content was also determined. These data show that total soluble tannins represent in average $93.3 \%$ and $90.2 \%$ of the total soluble phenolic content in plum flesh and peel, respectively. The content of total soluble tannins depended on cultivar, fruit tissue, and maturity. 'Pozna plava' showed the highest content of total soluble tannins, and 'Jojo' the lowest. Ripening resulted in lower total soluble tannins. The content of all analyzed phytochemicals in flesh was lower than that of peel. The fruit of the investigated cultivars contained up to 12-fold (flesh) and 22-fold (peel) more total insoluble than total soluble phenolic content.
\end{abstract}

\section{Keywords}

flesh, insoluble phenolics, maturity, soluble phenolics, peel

\section{Introduction}

The European plum (Prunus domestica L.) is the most taxonomically diverse of stone fruit, and it represents a rich source of nutrients and bioactive compounds (Tomás-Barberán et al., 2001). Plums are affected by the various diseases. In recent decades, most harmful disease of stone fruits across Europe and elsewhere in the world is Plum pox virus (PPV), which causes sharka disease (García et al., 2014). In past decades, scientists have looked intensely for new plum cultivars that show tolerance or resistance against PPV. However, these breeding trials have led to cultivars with an undesirable astringent taste (Hartmann and Neumüller, 2009), even when they are fully ripe.

Astringency is typical of some fruit species and unripe fruit, and along with other polyphenolic compounds (He et al., 2015), it is mainly due to soluble tannins (Salvador et al., 2007), and especially proanthocyanidins (Ashok and Upadhyaya, 2012). Tannins from food interact with mouth epithelium or salivary proteins and therefore astringency is perceived (Cheynier, 2012). Tannins are classified into hydrolysable and condensed tannins. The proanthocyanidins are synonymous with 'condensed tannins', and they are a group of plant secondary metabolites, as oligomers and polymers, which are derived through the flavonoid pathway (Hellström

\section{Significance of this study}

What is already known on this subject?

- The breeding of plum for resistance to sharka disease has also resulted in cultivars with an undesirable astringent taste, which is a known consequence of the presence of tannins.

\section{What are the new findings?}

- Tannins represent an important group of compounds in plum and are also a major part of the phenolics content in plum fruit. The content of total soluble tannins is affected by cultivar, maturity and fruit tissue.

What is the expected impact on horticulture?

- The results will contribute to knowledge about phenolic fractions in plums and also can be helpful for future plum breeding programs.

et al., 2009). They mostly comprise catechin, epicatechin, gallocatechin, and epigallocatechin (Ashok and Upadhyaya, 2012). The proanthocyanidins are the commonest group of tannins in most fruit species. Tannins, mostly bound nonextractable proanthocyanidins, represent a significant part of the insoluble fraction in aqueous organic solution of phenolic compounds (Zurita et al., 2012). When they are bound to polysaccharides and protein in plant cell walls (Zurita et al., 2012), they have no effects on astringency. Such insoluble phenolics are often indicated as nonextractable according to their solubility of extraction, and they are generally not included in analyses; however, they are a major and important constituent in food (Arranz et al., 2009; Pérez-Jiménez and Saura-Calixto, 2018; Zurita et al., 2012). Insoluble plus soluble phenolics are denoted as total phenolic content (Pérez-Jiménez et al., 2013).

Accumulation of tannins in different plant tissues (e.g., fruit peel, seed coating, grain, bark) provides the plants with protection against predators. The tannin content depends on the plant species and cultivar, the fruit maturity stage, and the temperature and other environmental conditions (He et al., 2015). Fruit known to have relatively high tannin contents, and particularly of proanthocyanidins, include persimmon (Del Bubba et al., 2009; Persic et al., 2019), grapes (Gu et al., 2004), quince (Silva et al., 2002), and others. The proanthocyanidins in plums have also been studied. Kristl et al. (2011) showed that the insoluble proanthocyanidins are major contributors to the antioxidant activities at different maturity stages in four plum cultivars ('Stanley', 'Valor', 'Hanita', 'Tophit'). Gu et al. (2004) identified plums as a potential source of A-type proanthocyanidins, and Jaiswal et al. (2013) also identified proanthocyanidins in plums ('Sat- 
suma', 'Jojo', 'Toptaste', 'Čačanska rodna', and others), and showed that they are the major phenolics present.

To the best of our knowledge, there are no studies in the literature regarding the total soluble tannins (TSTs) and total insoluble phenolic content (TiPC) in plum fruit in terms of fruit tissue and different maturities. The aim of the present study was to determine the effects of cultivar, fruit tissue and maturity on the content of total soluble tannins in plum fruit. Additionally, TiPC in the plum fruit were analyzed.

\section{Materials and methods}

\section{Chemicals}

The (-)-epicatechin (Fluka Chemie, Buchs, Switzerland) standard was used to identify the chemical compounds. Phenolics were extracted using methanol (Sigma-Aldrich Chemie GmbH, Steinheim, Germany) and double-distilled and purified water (Milli-Q purification system; Millipore, Bedford, MA, USA). The total soluble phenolic content (TsPC) and TiPC were determined using Folin-Ciocalteu phenol reagent (Fluka Chemie $\mathrm{GmbH}$ ), sodium carbonate (Acros Organics, ThermoFisher Scientific, Inc., Rockford, IL, USA), acetone (Sigma-Aldrich, Riedel-de Haen, Germany), hydrochloric acid (37\%; Sigma-Aldrich, Riedel-de Haen, Germany), n-butanol (Kemika, Zagreb, Croatia), and iron-III chloride hexahydrate, polyvinylpolypyrrolidone, and methanol (Sigma-Aldrich Chemie GmbH, Steinheim, Germany).

\section{Plant material}

Plum fruit were sampled from six-year-old plum trees (Prunus domestica L.) grafted on Myrobolan (Prunus cerasifera Ehrh.) rootstock, and growing at the Institute of Agriculture and Forestry Nova Gorica (Bilje, Slovenia; lat. $45.9^{\circ} \mathrm{N}$; long. $13.6^{\circ} \mathrm{E}$; alt. $48 \mathrm{~m}$ a.s.l.). The trees were spaced at $4 \mathrm{~m} \times$ $3 \mathrm{~m}$, trained in the 'palmette' form, and not irrigated. The average annual precipitation was $1,365 \mathrm{~mm}$. The fruit of three cultivars which differ according astringency were used. The taste of 'Pozna plava' plum is always astringent and of 'Jojo' only of less mature fruit. Astringency of 'Plumtastic' is usually not perceived. All cultivars have firm fruit of dark blue color of peel and yellow ('Plumtastic'), golden yellow ('Pozna plava') or orange flesh ('Jojo') at ripe stage. For each cultivar 30 fruit were hand-picked at the ripe stage, based on cultivar-specific peel color, from three-tree plots in September 2017.

\section{Ripening parameters}

The ripening parameters were measured immediately after picking. The hue angle of the peel $\left(h^{\circ}\right)$ was measured (Colour Reader CR-10 Croma meter; Konica Minolta, Japan; measuring diameter $6 \mathrm{~mm}$ ) for fruit with a preserved dusty wax coating on the right side opposite the fruit suture. The data are expressed in degrees, from $0^{\circ}$ to $360^{\circ}$. The firmness of the fruit was measured through the peel into the flesh (Penetrometer DFG 50; John Chatillion \& Sons, New York, USA; insertion depth $5 \mathrm{~mm}$ ), equipped with a round jagged stainless-steel probe (diameter $6 \mathrm{~mm}$ ).

After these measurements, fruit were put into numbered paper bags. Maturity classes were established based on measurements of the peel color. The fruit of each cultivar were selected and further grouped into maturity classes based on $h^{\circ}$ values. 'Pozna plava': A $\left(260^{\circ}-270^{\circ}\right)$, B $\left(270^{\circ}-280^{\circ}\right)$, and $\mathrm{C}\left(>280^{\circ}\right)$; 'Plumtastic': D $\left(258^{\circ}-262^{\circ}\right)$ and $\mathrm{E}\left(263^{\circ}-268^{\circ}\right)$; and 'Jojo': $\mathrm{F}\left(255^{\circ}-265^{\circ}\right), \mathrm{G}\left(265^{\circ}-285^{\circ}\right)$, and $\mathrm{H}\left(>285^{\circ}\right)$. The values of 'Plumtastic' were so similar that only two maturi- ty groups could be defined. Five fruit were selected for each maturity class of each cultivar $(n=5)$ for further analyses. Selected fruit were frozen and stored at $-20^{\circ} \mathrm{C}$ until further analysis.

The fruit were halved, and the stones were removed manually. Half of each fruit was used for extraction and determination of the phytochemicals (separately in the flesh and peel), and the other half for determination of the water content. All measurements were carried out on the same fruit. Soluble solids content $\left({ }^{\circ} \mathrm{Brix}\right)$ was measured in fruit juice, using a digital refractometer (WM-7; Atago Co. Ltd., Tokyo, Japan).

\section{Extraction and determination of soluble tannins}

The fruit flesh and peel were separately cut into small pieces. First, $3 \mathrm{~g}$ flesh and $0.5 \mathrm{~g}$ peel were extracted with $7 \mathrm{~mL}$ (for flesh) and $10 \mathrm{~mL}$ (for peel) $50 \%$ acidified aqueous methanol (pH 2 with $\mathrm{HCl}$ ). The extractions were carried out for $1 \mathrm{~h}$ at room temperature, with frequent stirring. The samples were then centrifuged for $10 \mathrm{~min}$ at $11,500 \times g(5810 \mathrm{R}$ centrifuge, Eppendorf), and $1 \mathrm{~mL}$ of each supernatant was filtered into a vial and kept stored in the cold. For the second extraction, the residue pellets were extracted again under

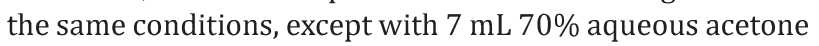
(70:30, v/v) (Zurita et al., 2012). The total soluble phenolic content (TsPC) of the combined extracts $(500 \mu \mathrm{L}$ of methanol and $500 \mu \mathrm{L}$ of acetone extract; 50:50, v/v) was determined using the Folin-Ciocalteu reagent method for determination of total phenolics (Singleton and Rossi, 1965), with spectrophotometric measurements of absorbance (UV-VIS Lambda Bio 20; PerkinElmer), at $765 \mathrm{~nm}$. The TsPC were calculated from the standard curve of epicatechin, and are expressed as epicatechin equivalents (EE) in milligrams per $100 \mathrm{~g} \mathrm{FW}$ (mg EE $100 \mathrm{~g}^{-1} \mathrm{FW}$ ). The combined extracts were used for determination of total soluble nontannins (TSnTs) using the tannin binding agent polyvinylpolypyrrolidone to precipitate the proanthocyanidins from the extract, according to the method described by Makkar et al. (1993), with some modifications. Here, to bind the tannins, $0.1 \mathrm{~g}$ polyvinylpolypyrrolidone was added to $500 \mu \mathrm{L}$ samples. Then, $1 \mathrm{~mL}$ double distilled and purified water (Milli-Q water purification system; Millipore, Bedford, MA, USA) was added. The samples were vortexed and left at $4^{\circ} \mathrm{C}$ for $10 \mathrm{~min}$. After this reaction, the samples were centrifuged at $11,500 \times g$ for $10 \mathrm{~min}$ at $4^{\circ} \mathrm{C}$. The supernatants were used for determination of the TSnTs fraction of the soluble phenolics using the Folin-Ciocalteu colorimetric reagent method (Singleton and Rossi, 1965), with spectrophotometric measurements of absorbance at $765 \mathrm{~nm}$ as before for the total phenolics. The TSnTs were calculated from the standard curve of epicatechin and are expressed as epicatechin equivalents (EE) in milligrams per $100 \mathrm{~g} \mathrm{FW}$ (mg EE $100 \mathrm{~g}^{-1} \mathrm{FW}$ ). The total soluble tannins (TSTs) were calculated as the difference between the TsPC and the TSnTs.

\section{Extraction and determination of total insoluble phenolics}

The extraction of the total insoluble phenolics was carried out according to the method previously described by $\mathrm{Zu}$ rita et al. (2012), with some modifications. Nonextractable phenolics are bounded to proteins and polysaccharides and they remain as residue pellets from aqueous organic procedure. The solid residue obtained from the extraction of the soluble phenolics was used to determine the total insoluble phenolic content (TiPC). The solid residues were dried in an oven at $30^{\circ} \mathrm{C}$ overnight. These dried residues were then each 
treated with $7 \mathrm{~mL}$ (for flesh) or $10 \mathrm{~mL}$ (for peel) HCl:butanol $(5: 95, \mathrm{v} / \mathrm{v})$ containing $0.7 \mathrm{~g}$ ferric chloride hexahydrate $\mathrm{L}^{-1}$. The solution was then vortexed and left in an oven at $100^{\circ} \mathrm{C}$ for $1 \mathrm{~h}$ to obtain cyanidin/delphinidin derived from the nonextractable proanthocyanidins. The extracts were left to cool at room temperature and were diluted prior to spectrophotometric analysis (50:50, v/v, with n-butanol).

The TiPC was quantified by measuring the anthocyanidins concentrations in the hydrolysates. Anthocyanidins and xanthylium compounds were quantified and summed according to absorbance at $555 \mathrm{~nm}$ and $450 \mathrm{~nm}$, respectively, using a spectrophotometer (UV-visible Lambda Bio 20; PerkinElmer). The TiPC was calculated from the standard curve of epicatechin, which was obtained using the epicatechin standard treated under the same conditions. Data are expressed as mg EE $100 \mathrm{~g}^{-1} \mathrm{FW}$.

\section{Statistical analysis}

Statistical analyses were processed using multifactor analysis of variance, where the factors were cultivar, fruit tissue, and maturity class. Analysis of the differences in the measured parameters across the different maturity classes of each cultivar were processed using one-way analysis of variance. The comparisons were made separately in relation to the maturity class for each cultivar. Differences were estimated with Duncan tests, where differences at $P<0.05$ were considered statistically significant. The statistical program $\mathrm{R}$ commander (v. 3.4.3) was used for the statistical analyses. Correlations among the phytochemicals were determined using Pearson's correlation coefficient tests.

\section{Results}

The maturity classes within each cultivar significantly differed only for peel $h^{\circ}$. Here, $h^{\circ}$ of 'Pozna plava' was higher for maturity class $C\left(292.4^{\circ} \pm 3.8^{\circ}\right)$ than maturity classes A $\left(265.7^{\circ} \pm 0.9^{\circ}\right)$ and $B\left(272.3^{\circ} \pm 1.0^{\circ}\right)$, for 'Plumtastic', it was higher for maturity class $\mathrm{E}\left(263.5^{\circ} \pm 0.6^{\circ}\right)$ than $\mathrm{D}\left(260.7^{\circ} \pm 0.3^{\circ}\right)$, and for 'Jojo', it was higher for maturity class $\mathrm{H}\left(307.4^{\circ} \pm 6.6^{\circ}\right)$ than $\mathrm{F}\left(261.9^{\circ} \pm 0.7^{\circ}\right)$ and $\mathrm{G}\left(267.9^{\circ} \pm 0.7^{\circ}\right)$. Water represents a large part of plum fruit, with $65 \%$ to $66.8 \%$ for 'Pozna plava', $69.5 \%$ for 'Plumtastic', and $75.9 \%$ to $77.8 \%$ for 'Jojo'. No differences in water content were seen across the maturity classes.

\section{Insoluble phenolics}

In general, the TiPC represented the greater part of the total phenolics content for the fruit of these three plum cultivars (Table 1). For the flesh, the TiPC represented $88.5 \%$ to $94.8 \%$ of the total phenolics content, and similarly for the peel, at $95.1 \%$ to $96.0 \%$ (Supplemental Figure S1). In general, the TiPC was 12 -fold (flesh) and 22-fold (peel) higher than the TsPC.

Significant differences were seen for the TiPC across the cultivars for both flesh and peel. For the flesh, 'Plumtastic'

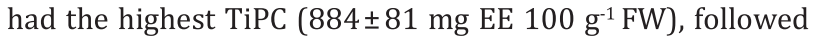
by 'Pozna plava' (534 $\pm 51 \mathrm{mg}$ EE $100 \mathrm{~g}^{-1} \mathrm{FW}$ ) and 'Jojo' $\left(299 \pm 22 \mathrm{mg}\right.$ EE $\left.100 \mathrm{~g}^{-1} \mathrm{FW}\right)$. For the peel, the highest TiPC

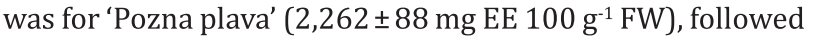
by 'Plumtastic' $\left(1,965 \pm 161 \mathrm{mg}\right.$ EE $\left.100 \mathrm{~g}^{-1} \mathrm{FW}\right)$ and 'Jojo' $\left(1,585 \pm 174 \mathrm{mg}^{\mathrm{EE}} 100 \mathrm{~g}^{-1} \mathrm{FW}\right)$. In general, these data show that the plum maturity class did not affect the TiPC (Table 1). The only exception was for the flesh of 'Plumtastic' for maturity class D (i.e., the lower $h^{\circ}$ ), where the TiPC was $21.7 \%$ lower than for maturity class $\mathrm{E}$.

\section{Soluble phenolics}

The TsPC represented the minority of phenolics in these plum fruits. Overall, the relative content of the TsPC in the plum flesh was $8.8 \%$ and in the plum peel it was $4.4 \%$ (Supplemental Figure S1). Compared to the flesh, the TsPC in peel

TABLE 1. Phenolics, tannin, and nontannin content (mean \pm standard error in $\mathrm{mg}$ EE $100 \mathrm{~g}^{-1} \mathrm{FW}$ ) in flesh and peel of the three plum cultivars according to maturity class.

\begin{tabular}{|c|c|c|c|c|c|c|}
\hline \multirow[t]{2}{*}{ Tissue } & \multirow[t]{2}{*}{ Cultivar } & \multirow[t]{2}{*}{ Maturity class ${ }^{*}$} & \multicolumn{2}{|c|}{$\begin{array}{l}\text { Total phenolics content } \\
\left.\text { (mg EE } 100 \mathrm{~g}^{-1} \mathrm{FW}\right)\end{array}$} & \multirow{2}{*}{$\begin{array}{l}\text { Total soluble tannins } \\
\left(\mathrm{mg} \text { EE } 100 \mathrm{~g}^{-1} \mathrm{FW}\right)\end{array}$} & \multirow{2}{*}{$\begin{array}{l}\text { Total soluble nontannins } \\
\left.\text { (mg EE } 100 \mathrm{~g}^{-1} \mathrm{FW}\right)\end{array}$} \\
\hline & & & Insoluble & Soluble & & \\
\hline \multirow[t]{8}{*}{ Flesh } & 'Pozna plava' & $A$ & $545.7 \pm 115.1 \mathrm{Ba}$ & $57.9 \pm 3.0 \mathrm{Aa}$ & $54.2 \pm 2.9 \mathrm{Aa}$ & $3.6 \pm 0.2 \mathrm{Aa}$ \\
\hline & & B & $566.1 \pm 88.6 \mathrm{Ba}$ & $61.1 \pm 4.2 \mathrm{Aa}$ & $57.6 \pm 4.1 \mathrm{Aa}$ & $3.5 \pm 0.1 \mathrm{Aa}$ \\
\hline & & C & $591.9 \pm 76.2 \mathrm{Ba}$ & $61.9 \pm 2.6 \mathrm{Aa}$ & $58.2 \pm 2.5 \mathrm{Aa}$ & $3.6 \pm 0.2 \mathrm{Aa}$ \\
\hline & 'Plumtastic' & D & $791.4 \pm 69.8 \mathrm{Ab}$ & $49.6 \pm 1.7 \mathrm{Ba}$ & $45.9 \pm 1.6 \mathrm{Ba}$ & $3.6 \pm 0.1 \mathrm{Aa}$ \\
\hline & & $E$ & $1,080.9 \pm 64.9 \mathrm{Aa}$ & $53.8 \pm 3.3 \mathrm{Ba}$ & $50.0 \pm 3.2 \mathrm{Ba}$ & $3.8 \pm 0.1 \mathrm{Aa}$ \\
\hline & 'Jojo' & $\mathrm{F}$ & $308.7 \pm 28.4 \mathrm{Ca}$ & $37.6 \pm 2.3 \mathrm{Ca}$ & $34.8 \pm 2.2 \mathrm{Ca}$ & $2.8 \pm 0.1 \mathrm{Ba}$ \\
\hline & & G & $260.9 \pm 38.6 \mathrm{Ca}$ & $38.9 \pm 4.8 \mathrm{Ca}$ & $36.2 \pm 4.7 \mathrm{Ca}$ & $2.6 \pm 0.1 \mathrm{Ba}$ \\
\hline & & $\mathrm{H}$ & $326.9 \pm 47.8 \mathrm{Ca}$ & $33.8 \pm 4.0 \mathrm{Ca}$ & $31.4 \pm 3.9 \mathrm{Ca}$ & $2.5 \pm 0.1 \mathrm{Ba}$ \\
\hline \multirow[t]{8}{*}{ Peel } & 'Pozna plava' & $A$ & $2,062.9 \pm 209.6 \mathrm{Aa}$ & $77.6 \pm 4.2 \mathrm{Ab}$ & $68.5 \pm 4.3 \mathrm{Ac}$ & $8.1 \pm 0.7 \mathrm{Ba}$ \\
\hline & & B & $2,241.9 \pm 84.8 \mathrm{Aa}$ & $84.1 \pm 7.0 \mathrm{Ab}$ & $76.5 \pm 7.1 \mathrm{Ab}$ & $7.6 \pm 0.4 \mathrm{Ba}$ \\
\hline & & C & $2,481.1 \pm 88.9 \mathrm{Aa}$ & $122.5 \pm 16.3 \mathrm{Aa}$ & $113.9 \pm 16.3 \mathrm{Aa}$ & $8.5 \pm 0.3 \mathrm{Ba}$ \\
\hline & 'Plumtastic' & D & $1,856.2 \pm 292.3 \mathrm{Ba}$ & $82.9 \pm 5.8 \mathrm{Aa}$ & $74.9 \pm 5.8 \mathrm{Aa}$ & $8.0 \pm 0.6 \mathrm{ABa}$ \\
\hline & & E & $2,020.0 \pm 132.7 \mathrm{Ba}$ & $87.2 \pm 5.1 \mathrm{Aa}$ & $79.0 \pm 4.9 \mathrm{Aa}$ & $8.2 \pm 0.3 \mathrm{ABa}$ \\
\hline & 'Jojo' & $\mathrm{F}$ & $1,208.5 \pm 165.1 \mathrm{Ca}$ & $69.7 \pm 9.8 \mathrm{Aa}$ & $59.9 \pm 9.9 \mathrm{Aa}$ & $9.8 \pm 0.8 \mathrm{Aab}$ \\
\hline & & G & $1,978.9 \pm 354.4 \mathrm{Ca}$ & $84.6 \pm 5.7 \mathrm{Aa}$ & $76.8 \pm 5.5 \mathrm{Aa}$ & $7.8 \pm 0.2 \mathrm{Ab}$ \\
\hline & & $\mathrm{H}$ & $1,567.4 \pm 303.3 \mathrm{Ca}$ & $89.2 \pm 15.2 \mathrm{Aa}$ & $79.0 \pm 15.3 \mathrm{Aa}$ & $10.2 \pm 0.8 \mathrm{Aa}$ \\
\hline
\end{tabular}

A: Data followed by different capital letters within plum tissue indicate statistically significant differences across the cultivars $(P<0.05$; Duncan test). a: Data followed by different small letters within plum tissue indicate statistically significant differences across the maturity classes of each cultivar $(\mathrm{P}<0.05$; Duncan test).

${ }^{*}$ For defined maturity classes, see Materials and methods. 
was higher, as 1.6-fold, 1.6-fold, and 2.2-fold for 'Pozna plava', 'Plumtastic', and 'Jojo', respectively (Table 1). There were significant differences for the TsPC in the flesh across the cultivars, with the TsPC for 'Pozna plava' $\left(60.3 \pm 1.8 \mathrm{mg}^{2} \mathrm{EE} 100 \mathrm{~g}^{-1}\right.$ FW) was higher than 'Plumtastic' $\left(51.7 \pm 2.3\right.$ mg EE $100 \mathrm{~g} \mathrm{~g}^{-1}$ FW) and 'Jojo' ( $36.8 \pm 2.1 \mathrm{mg}$ EE $100 \mathrm{~g}^{-1} \mathrm{FW}$ ) (Table 1). The TsPC in the 'Pozna plava', 'Plumtastic', and 'Jojo' peel were $94.4 \pm 7.7 \mathrm{mg}^{2} \mathrm{EE} 100 \mathrm{~g} \mathrm{~g}^{-1} \mathrm{FW}, 84.6 \pm 4.2 \mathrm{mg}^{\mathrm{EE}} 100 \mathrm{~g}^{-1} \mathrm{FW}$, and $81.2 \pm 6.2 \mathrm{mg}$ EE $100 \mathrm{~g}^{-1} \mathrm{FW}$, respectively. Significant differences for the TsPC across the maturity classes were seen for the 'Pozna plava' peel, where maturity class $\mathrm{C}$ showed higher TsPC than maturity classes A and B (by $31.3 \%-36.6 \%$ ) (Table 1).

\section{Soluble tannins}

The TSTs represented a substantial fraction of the TsPC in the flesh and peel of all three of the cultivars. The relative TST levels overall (compared to TsPC) were 93.3\% for flesh and $90.2 \%$ for peel. These data show that in absolute values, the TSTs of 'Pozna plava', 'Plumtastic', and 'Jojo' were lower in the plum flesh than in the plum peel, by about half to two-thirds. The 'Pozna plava' flesh showed significantly higher TSTs (56.7 $\pm 1.8 \mathrm{mg}$ EE $100 \mathrm{~g}^{-1} \mathrm{FW} ; 94.1 \%$ of flesh TsPC) than 'Plumtastic' $\left(48.0 \pm 2.2 \mathrm{mg}\right.$ EE $100 \mathrm{~g}^{-1} \mathrm{FW} ; 92.7 \%$ of flesh TsPC), and 'Jojo' (34.1 $\pm 2.1 \mathrm{mg} \mathrm{EE} 100 \mathrm{~g}^{-1} \mathrm{FW}$; 93.1\% of flesh TsPC). The TSTs in the 'Pozna plava', 'Plumtastic', and 'Jojo' peel were $86.3 \pm 7.7,77 \pm 4.1$ and $71.9 \pm 6.3 \mathrm{mg} \mathrm{EE} 100 \mathrm{~g}^{-1} \mathrm{FW}$, respectively. Although in the flesh there were no differences across the maturity classes within the cultivars, the maturity class had a significant influence on TSTs in the peel of 'Pozna plava' (Table 1). Here, maturity class A had 39.8\% lower TSTs $\left(68.5 \pm 4.3 \mathrm{mg}\right.$ EE $\left.100 \mathrm{~g}^{-1} \mathrm{FW}\right)$ than class B $(76.5 \pm 7.1 \mathrm{mg}$ EE $100 \mathrm{~g}^{-1} \mathrm{FW}$ ), which had $10.4 \%$ lower TSTs than class C

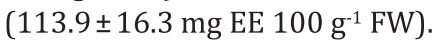

\section{Total soluble nontannins}

The TSnTs represented a minor part of the TsPC (Supplemental Figure S1). Overall, the TSnTs in the plum flesh were about a third of those in the plum peel. The peel from 'Jojo' had the highest TSnTs $\left(9.3 \pm 0.4 \mathrm{mg}\right.$ EE $100 \mathrm{~g}^{-1} \mathrm{FW} ; 11.3 \%$ of TsPC). The TSnTs were lower than the TSTs contents both in flesh (14-fold) and peel (9.3-fold).

\section{Correlations between the measured parameters}

One of the aims of the present study was to determine how the TSTs correlate with the other phytochemicals determined here. These data show that the TSTs were correlated with TsPC $(r=0.99)$ in both the plum flesh and peel (Table 2$)$. Lower correlation coefficients were obtained between TsPC and TSnTs in the flesh of all three of the cultivars ('Pozna plava', 0.52; 'Plumtastic', 0.66; 'Jojo', 0.80).

\section{Discussion}

In plum, the fruit color is one of the main indicators of maturity (Usenik et al., 2014). This classification of the fruit according to color thus defines the distribution into different maturity stages (Usenik et al., 2014). Here, the hue angle $\left(h^{\circ}\right)$ is therefore the main criterion used. The $h^{\circ}$ defines the basic tone of the color, where values around $270^{\circ}$ represented a blue color, and around $300^{\circ}$, magenta. The $h^{\circ}$ of less ripe

TABLE 2. Pearson correlations between phenolics, tannin, and nontannin content in flesh and peel of the three plum cultivars.

\begin{tabular}{|c|c|c|c|c|c|c|}
\hline \multirow[b]{2}{*}{ Cultivar } & \multirow[b]{2}{*}{ Tissue } & \multirow[b]{2}{*}{ Measure } & \multicolumn{4}{|c|}{ Pearson correlation } \\
\hline & & & $\begin{array}{c}\text { Total insoluble } \\
\text { phenolics } \\
\text { content }\end{array}$ & $\begin{array}{l}\text { Total soluble } \\
\text { phenolics } \\
\text { content }\end{array}$ & $\begin{array}{l}\text { Total } \\
\text { soluble } \\
\text { tannins }\end{array}$ & $\begin{array}{c}\text { Total } \\
\text { soluble } \\
\text { nontannins }\end{array}$ \\
\hline \multirow[t]{8}{*}{ 'Pozna plava' } & Flesh & Total insoluble phenolics content & & 0.1570 & 0.1910 & -0.5480 \\
\hline & & Total soluble phenolics content & 0.1570 & & 0.9989 & 0.5189 \\
\hline & & Total soluble tannins & 0.1910 & 0.9989 & & 0.4786 \\
\hline & & Total soluble nontannins & -0.5480 & 0.5189 & 0.4786 & \\
\hline & Peel & Total insoluble phenolics content & & 0.4035 & 0.4129 & -0.1133 \\
\hline & & Total soluble phenolics content & 0.4035 & & 0.9993 & 0.3407 \\
\hline & & Total soluble tannins & 0.4129 & 0.9993 & & 0.3062 \\
\hline & & Total soluble nontannins & -0.1133 & 0.3407 & 0.3062 & \\
\hline \multirow[t]{8}{*}{ 'Plumtastic' } & Flesh & Total insoluble phenolics content & & 0.5482 & 0.5456 & 0.4138 \\
\hline & & Total soluble phenolics content & 0.5482 & & 0.9995 & 0.6585 \\
\hline & & Total soluble tannins & 0.5456 & 0.9995 & & 0.6337 \\
\hline & & Total soluble nontannins & 0.4138 & 0.6585 & 0.6337 & \\
\hline & $\overline{\text { Peel }}$ & Total insoluble phenolics content & & -0.1703 & -0.1552 & -0.2469 \\
\hline & & Total soluble phenolics content & -0.1703 & & 0.9974 & 0.3178 \\
\hline & & Total soluble tannins & -0.1552 & 0.9974 & & 0.2490 \\
\hline & & Total soluble nontannins & -0.2469 & 0.3178 & 0.2490 & \\
\hline \multirow[t]{8}{*}{ 'Jojo' } & Flesh & Total insoluble phenolics content & & 0.2317 & 0.2606 & 0.5650 \\
\hline & & Total soluble phenolics content & 0.4555 & & 0.9996 & 0.7973 \\
\hline & & Total soluble tannins & 0.4453 & 0.9996 & & 0.7789 \\
\hline & & Total soluble nontannins & 0.5650 & 0.7973 & 0.7789 & \\
\hline & $\overline{\text { Peel }}$ & Total insoluble phenolics content & & 0.2317 & 0.2606 & -0.4173 \\
\hline & & Total soluble phenolics content & 0.2317 & & 0.9974 & -0.0341 \\
\hline & & Total soluble tannins & 0.2606 & 0.9974 & & -0.1060 \\
\hline & & Total soluble nontannins & -0.4173 & -0.0341 & -0.1060 & \\
\hline
\end{tabular}


plums is higher than that of more ripe fruit (Usenik et al., 2014). Similar data were also reported by Gonçalves et al. (2007) for sweet cherry. The present study shows lower contents of all of these analyzed phenolics in the plum flesh than in the plum peel. Several studies have also reported lower flesh phenolic contents than for peel, such as for plums (Cosmulescu et al., 2015; Usenik et al., 2013), peaches (Dabbou et al., 2017), peaches, and nectarines (Tomás-Barberán et al., 2001). Such high phenolic contents in fruit peel appears to be because the phenolics tend to accumulate in the epidermis of plants, according to their potential role in plant protection (Dixon and Paiva, 1995). Additionally, flavonols and anthocyanins are mainly seen for the fruit peel (Renard et al., 2007).

These data show that plum fruit have higher TiPC than TsPC, which has also been reported for apples, nectarines, and peaches (Pérez-Jiménez et al., 2013), where the TiPC represented 90\% (apples, nectarines) and 80\% (peaches) of the total phenolics content. The present data are also in agreement with Persic et al. (2019), who reported 1.6-fold and 2.3-fold higher TiPC than TsPC for the peel of astringent (unripe) and mellowed persimmon, respectively, of the 'Tipo' cultivar. Evidently, even after mellowing of persimmon, the TiPC represents a majority fraction of the phenolics, and especially the bound proanthocyanidins. Arranz et al. (2009) reported that the TiPC in the edible parts of apples, peaches, and nectarines was 5.9-fold higher than the TsPC. The present study shows a higher ratio between TiPC and TsPC, which would appear to be due to differences in the phenolic profile of this fruit species.

Overall, the peel of analyzed plum cultivars had 2-5fold higher TiPC than the flesh. Although the peel is an excellent source of phenolics, it only represents $3.2 \%$ to $8.4 \%$ of fruit weight (Cosmulescu et al., 2015). Pérez-Jiménez and Saura-Calixto (2018) reported that peel TiPC contributions to the total polyphenols in whole fruit were $>40 \%$ for nectarine, orange, and mandarin. The highest contributions of the peel TiPC to the total phenolics content in peel have been obtained for pear, kiwi, and orange $(70 \%, 79 \%, 80 \%$, respectively). It is often erroneously assumed that the term total phenolics content is frequently used only for the soluble phenolics, although it includes both TsPC and TiPC. Of these, the TiPC is the major constituent in food, although this has generally been ignored. Thus, it is becoming evident that the TiPC is higher than the TsPC in many foods (Pérez-Jiménez and Torres, 2011).

The maturity class of these plums showed significant influence on the TiPC only in the flesh of the 'Plumtastic' cultivar, where the TiPC decreased with lower $h^{\circ}$. Few data are to be found in the literature concerning changes in the TiPC across different maturity stages in plums. Only Kristl et al. (2011) have shown that the TiPC decreases during the last few days of ripening of plums.

Overall, the TsPC was lower in the plum flesh compared to the plum peel. Similar data were reported by Cosmulescu et al. (2015) for 12 plum cultivars. Such higher phenolics content for peel was also further reported for plums ('Jojo', 'Haganta') (Usenik et al., 2013), and for nectarines, peaches, and plums (Gil et al., 2002). In the present study, there were nonsignificant differences across the three plum cultivars for the TsPC in the peel, which was possibly due to the high variability of these data. The TsPC in the plum peel here varied across the cultivars from 81.2 to $94.4 \mathrm{mg}$ EE $100 \mathrm{~g}^{-1} \mathrm{FW}$ while for the flesh, this range was from 36.8 to $60.3 \mathrm{mg} \mathrm{EE}$ $100 \mathrm{~g}^{-1} \mathrm{FW}$. These higher phenolics contents in peel are probably due to the anthocyanins present in the peel. This is in agreement with Usenik et al. (2013), who showed that for plum, $h^{\circ}$ is significantly correlated with total anthocyanins, and Rupasinghe et al. (2006), who reported a correlation of $h^{\circ}$ with TsPC for plum. In the flesh of the plums in the present study, a significant trend in the TsPC was seen across the cultivars, which is in agreement with Cosmulescu et al. (2015), who reported differences in flesh TsPC across their analyzed plum cultivars. Differences across plum cultivars for the TsPC have also been reported in some other studies (Rop et al., 2009; Rupasinghe et al., 2006).

The differences seen in the present study across the maturity classes for the TsPC of the fruit flesh were not significant, while for the fruit peel of 'Pozna plava', maturity classes A and B had lower TsPC than maturity class C. Such decreases in the TsPC with ripening have been reported for medlar (Ayaz et al., 2008), blueberry (Castrejón et al., 2008), and other fruit. Miletic et al. (2012) also noted a significant decreasing trend in the TsPC between the last two ripening stages in the 'Stanley' plum cultivar.

Nevertheless, the main purpose of this study was to ascertain the presence of TSTs in plum. For the TSTs in plum, there are no data that have associated these with astringency. Some studies have reported only on proanthocyanidins (Gu et al., 2004; Hellström et al., 2009), although plums are also a rich source of hydrolysable tannins (Arranz et al., 2010). The present study shows that the fruit of all three of these plum cultivars contained tannins, with less in the flesh than the peel. The TSTs of the peel of the 'Pozna plava,' 'Plumtastic', and 'Jojo' cultivars were on average 1.5-fold, 1.6-fold, and 2.1-fold higher than for the flesh. This is in agreement with the concept that tannins are mainly located in fruit peel, where they are reactive and easily extractible (He et al., 2015). Within the same species or cultivars, the tannins content can vary between the different parts of the fruit. In the literature, there have been reports that extracts of fruit peel have higher contents of tannins than those of fruit flesh, as for pomegranate (Li et al., 2006), grape (Sparrow et al., 2015), and others.

The present study also shows significant differences across the three plum cultivars for the TSTs of the fruit flesh, where 'Pozna plava' showed the highest values. For the fruit peel here, there were no significant differences seen across the three plum cultivars. According to the literature, tannin levels differ across fruit cultivars, and they also depend on the maturity stage (De Pascual-Teresa et al., 2000). Tannins have mostly been reported, in higher amounts, for persimmon (Del Bubba et al., 2009), chokeberry (Gu et al., 2004), and pomegranate (Abid et al., 2017), where they showed higher levels than for the plum fruit analyzed in the present study.

Our study showed differences in the TSTs across the plum maturity classes, although significance was only reached for the 'Pozna plava' peel, where the TSTs decreased with decreasing $h^{\circ}$. The tannins contents have also been seen to decrease in progression of ripening for persimmon (Del Bubba et al., 2009) and other berry species (Jaakola et al., 2002; Zhang et al., 2010). In studies of other fruit species and in agreement with the present study, the tannins contents are higher in the earlier stages of fruit growth and development and decline during the final ripening process (Bindon and Kennedy, 2011; Hanlin and Downey, 2009). Otherwise, there have also been reports of increasing tannins content during ripening for the skin and juice of muscadine grapes (Vitis rotundifolia) (Lee and Talcott, 2004). These studies all demonstrate that reduction or accumulation of tannins during the 
ripening process can vary across fruit species. In addition, the tannins content can vary according to other seasonal and environmental factors (He et al., 2015).

It is known that decreased TSTs during fruit maturation is related to the loss of astringency (Lestario et al., 2017). Also, it has been speculated that polymerization of tannins during ripening of fruit, and their binding to cell proteins and cell-wall polysaccharides greatly decrease their solubility, and the astringency (Goldstein and Swain, 1963). However, although decreased, the TSTs apparently still remained in contents where the astringency can be perceived.

The data from the present study suggest that the TSTs are the most important contributors to the TsPC $(r=0.99)$ in the fruit of all three of these plum cultivars. Here, the TSTs ranged from $92.7 \%$ to $94.1 \%$ for the plum flesh, and $88.7 \%$ to $91.5 \%$ for the plum peel, in terms of the TsPC. These data are similar to those of Persic et al. (2019), who showed that the TSTs in the 'Tipo' and 'Rojo Brillante' persimmon cultivars represented the major fraction of the TsPC after mellowing (82.5\%, 80.0\%, respectively). Abid et al. (2017) reported that in pomegranate, the polyphenols consist mostly of tannins, at about $90 \%$ to $95 \%$.

The present study shows that tannins represent an important group of compounds in plum fruit. In some plum cultivars, the tannins contribute to the perception of the fruit in the mouth, and they will therefore also possibly affect the responses of consumers. Tannins were also present in the fruit of plum cultivars where astringency is not perceived. Although for the relatively high TSTs in the fruit of 'Plumtastic' and 'Jojo' cultivars here, their particular astringency has not been perceived (data not shown). Indeed, future studies should be designed to answer to the question of what specifically determines the feeling of astringency in the taste of such fruit. Is it determined by the concentrations of the tannins in the tissues, by the reduced concentrations of the tannins in the peel, by the proportions of the tannins in the fruit tissues, or by the ratios between the different phytochemicals in the fruit?

\section{Conclusions}

In summary, the fruit of three investigated plum cultivars thus contain soluble tannins that act as a major contributor to the TsPC. The present study shows significant effects of cultivar and fruit tissue on the plum phenolic profiles (as TiPC, TsPC, TSTs). The highest tannins content was shown for the 'Pozna plava' fruit, which shows a very distinct astringency. The content of all of the analyzed phenolics were lower in the fruit flesh than peel. Additionally, the TiPC represents the majority of the phenolics in all three of these plum cultivars. As the TSTs represent about $90 \%$ of the TsPC, the TsPC also differed across these three plum cultivars. The differences in the TSTs across the maturity classes here were mainly not significant, but indicated lower TSTs in the more mature fruit, both for the flesh and peel, although with some exceptions. Ripening resulted in significantly lower TSTs for the 'Pozna plava' fruit peel.

\section{Acknowledgments}

This work was supported by the Slovenian Research Agency (ARRS), Young Researchers Program (MV) and research core funding no. P4-0013 (MV, MP, RV, VU). The authors would like to thank Fruit Growing Center Bilje for the plum fruit.

\section{Conflict of interest statement}

There is no financial/personal interest or belief that could affect the objectivity of the study.

\section{References}

Abid, M., Yaich, H., Cheikhrouhou, S., Khemakhem, I., Bouaziz, M., Attia, H., and Ayadi, M. (2017). Antioxidant properties and phenolic profile characterization by LC-MS/MS of selected Tunisian pomegranate peels. J. Food Sci. Technol. 54, 2890-2901. https://doi. org/10.1007/s13197-017-2727-0.

Arranz, S., Saura-Calixto, F., Shaha, S., and Kroon, P.A. (2009). High contents of nonextractable polyphenols in fruits suggest that polyphenol contents of plant foods have been underestimated. J. Agric. Food Chem. 57, 7298-7303. https://doi.org/10.1021/ jf9016652.

Arranz, S., Silván, J.M., and Saura-Calixto, F. (2010). Nonextractable polyphenols, usually ignored, are the major part of dietary polyphenols: A study on the Spanish diet. Mol. Nutr. Food Res. 54, 1646-1658. https://doi.org/10.1002/mnfr.200900580.

Ashok, P.K., and Upadhyaya, K. (2012). Tannins are astringent. J. Pharmacogn. Phytochem. 1, 45-50.

Ayaz, F., Demir, O., Torun, H., Kolcuoglu, Y., and Colak, A. (2008). Characterization of polyphenoloxidase (PPO) and total phenolic contents in medlar (Mespilus germanica L.) fruit during ripening and over ripening. Food Chem. 106, 291-298. https://doi.org/10.1016/j. foodchem.2007.05.096.

Bindon, K.A., and Kennedy, J.A. (2011). Ripening-induced changes in grape skin proanthocyanidins modify their interaction with cell walls. J. Agric. Food Chem. 59, 2696-2707. https://doi.org/10.1021/ jf1047207. https://doi.org/10.1021/jf1047207.

Castrejón, A.D.R., Eichholz, I., Rohn, S., Kroh, L.W., and HuyskensKeil, S. (2008). Phenolic profile and antioxidant activity of highbush blueberry (Vaccinium corymbosum L.) during fruit maturation and ripening. Food Chem. 109, 564-572. https://doi.org/10.1016/j. foodchem.2008.01.007.

Cheynier, V. (2012). Phenolic compounds: from plants to foods. Phytochem. Rev. 11, 153-177. https://doi.org/10.1007/s11101012-9242-8.

Cosmulescu, S., Trandafir, I., Nour, V., and Botu, M. (2015). Total phenolic, flavonoid distribution and antioxidant capacity in skin, pulp and fruit extracts of plum cultivars. J. Food Biochem. 39, 64-69. https://doi.org/10.1111/jfbc.12112.

Dabbou, S., Maatallah, S., Castagna, A., Guizani, M., Sghaeir, W., Hajlaoui, H., and Ranieri, A. (2017). Carotenoids, phenolic profile, mineral content and antioxidant properties in flesh and peel of Prunus persica fruits during two maturation stages. Plant Foods Hum. Nutr. 72, 103-110. https://doi.org/10.1007/s11130-0160585-y

De Pascual-Teresa, S., Santos-Buelga, C., and Rivas-Gonzalo, J.C. (2000). Quantitative analysis of Flavan-3-ols in Spanish foodstuffs and beverages. J. Agric. Food Chem. 48, 5331-5337. https://doi. org/10.1021/jf000549h

Del Bubba, M., Giordani, E., Pippucci, L., Cincinelli, A., Checchini, L., and Galvan, P. (2009). Changes in tannins, ascorbic acid and sugar content in astringent persimmons during on-tree growth and ripening and in response to different postharvest treatments. J. Food Compost. Anal. 22, 668-677. https://doi.org/10.1016/j. jfca.2009.02.015

Dixon, R.A., and Paiva, N.L. (1995). Stress-induced phenylpropanoid metabolism. Plant Cell 7, 1085. https://doi.org/10.1105/ tpc.7.7.1085.

García, J.A., Glasa, M., Cambra, M., and Candresse, T. (2014). Plum pox virus and sharka: A model potyvirus and a major disease. Mol. Plant Pathol. 15, 226-241. https://doi.org/10.1111/mpp.12083.

Gil, M.I., Tomás-Barberán, F.A., Hess-Pierce, B., and Kader, A.A. (2002). Antioxidant capacities, phenolic compounds, carotenoids, 
and vitamin $\mathrm{C}$ contents of nectarine, peach, and plum cultivars from California. J. Agric. Food Chem. 50, 4976-4982. https://doi. org/10.1021/jf020136b.

Goldstein, J.L., and Swain, T. (1963). Changes in tannins in ripening fruits. Phytochemistry 2, 371-383. https://doi.org/10.1016/S00319422(00)84860-8.

Gonçalves, B., Silva, A.P., Moutinho-Pereira, J., Bacelar, E., Rosa, E., and Meyer, A.S. (2007). Effect of ripeness and postharvest storage on the evolution of colour and anthocyanins in cherries (Prunus avium L.). Food Chem. 103, 976-984. https://doi.org/10.1016/j. foodchem.2006.08.039

Gu, L., Kelm, M.A., Hammerstone, J.F., Beecher, G., Holden, J., Haytowitz, D., Gebhardt, S., and Prior, R.L. (2004). Concentrations of proanthocyanidins in common foods and estimations of normal consumption. J. Nutr. 134, 613-617. https://doi.org/10.1093/ jn/134.3.613.

Hanlin, R.L., and Downey, M.O. (2009). Condensed tannin accumulation and composition in skin of Shiraz and Cabernet Sauvignon grapes during berry development. Am. J. Enol. Vitic. 60, 13-23.

Hartmann, W., and Neumüller, M. (2009). Plum breeding. In Breeding Plantation Tree Crops: Temperate Species, S.M. Jain, and P.M. Priyadarshan, eds. (Singapore: Springer), p. 161-231. https://doi. org/10.1007/978-0-387-71201-7.

He, M., Tian, H., Luo, X., Qi, X., and Chen, X. (2015). Molecular progress in research on fruit astringency. Molecules 20,1434-1451. https:// doi.org/10.3390/molecules20011434.

Hellström, J.K., Torronen, A.R., and Mattila, P.H. (2009). Proanthocyanidins in common food products of plant origin. J. Agric. Food Chem. 57, 7899-7906. https://doi.org/10.1021/jf901434d.

Jaakola, L., Määttä, K., Pirttilä, A.M., Törrönen, R., Kärenlampi, S., and Hohtola, A. (2002). Expression of genes involved in anthocyanin biosynthesis in relation to anthocyanin, proanthocyanidin, and flavonol levels during bilberry fruit development. Plant Physiol. 130, 729-739. https://doi.org/10.1104/pp.006957.

Jaiswal, R., Karaköse, H., Rühmann, S., Goldner, K., Neumüller, M., Treutter, D., and Kuhnert, N. (2013). Identification of phenolic compounds in plum fruits (Prunus salicina L. and Prunus domestica L.) by high-performance liquid chromatography/tandem mass spectrometry and characterization of varieties by quantitative phenolic fingerprints. J. Agric. Food Chem. 61, 12020-12031. https://doi.org/10.1021/jf402288j.

Kristl, J., Slekovec, M., Tojnko, S., and Unuk, T. (2011). Extractable antioxidants and non-extractable phenolics in the total antioxidant activity of selected plum cultivars (Prunus domestica L.): Evolution during on-tree ripening. Food Chem. 125, 29-34. https://doi. org/10.1016/j.foodchem.2010.08.027.

Lee, J.-H., and Talcott, S.T. (2004). Fruit maturity and juice extraction influences ellagic acid derivatives and other antioxidant polyphenolics in muscadine grapes. J. Agric. Food Chem. 52, 361366. https://doi.org/10.1021/jf034971k.

Lestario, L.N., Howard, L.R., Brownmiller, C., Stebbins, N.B., Liyanage, R., and Lay, J.O. (2017). Changes in polyphenolics during maturation of Java plum (Syzygium cumini Lam.). Food Res. Int. 100, 385-391. https://doi.org/10.1016/j.foodres.2017.04.023.

Li, Y., Guo, C., Yang, J., Wei, J., Xu, J., and Cheng, S. (2006). Evaluation of antioxidant properties of pomegranate peel extract in comparison with pomegranate pulp extract. Food Chem. 96, 254-260. https:// doi.org/10.1016/j.foodchem.2005.02.033.

Makkar, H.P., Blümmel, M., Borowy, N.K., and Becker, K. (1993). Gravimetric determination of tannins and their correlations with chemical and protein precipitation methods. J. Sci. Food Agric. 61, 161-165. https://doi.org/10.1002/jsfa.2740610205.
Miletic, N., Popovic, B., Mitrovic, O., and Kandic, M. (2012). Phenolic content and antioxidant capacity of fruits of plum cv. 'Stanley' (Prunus domestica L.) as influenced by maturity stage and on-tree ripening. Aust. J. Crop. Sci. 6, 681-687.

Pérez-Jiménez, J., and Torres, J.L. (2011). Analysis of nonextractable phenolic compounds in foods: the current state of the art. J. Agric. Food Chem. 59, 12713-12724. https://doi.org/10.1021/jf203372w.

Pérez-Jiménez, J., and Saura-Calixto, F. (2018). Fruit peels as sources of non-extractable polyphenols or macromolecular antioxidants: Analysis and nutritional implications. Food Res. Int. 111, 148-152. https://doi.org/10.1016/j.foodres.2018.05.023.

Pérez-Jiménez, J., Díaz-Rubio, M.E., and Saura-Calixto, F. (2013). Nonextractable polyphenols, A major dietary antioxidant: occurrence, metabolic fate and health effects. Nutr. Res. Rev. 26, 118-129. https://doi.org/10.1017/S0954422413000097.

Persic, M., Jakopic, J., and Hudina, M. (2019). The effect of postharvest technologies on selected metabolites in persimmon (Diospyros kaki Thunb.) fruit. J. Sci. Food Agric. 99, 854-860. https:// doi.org/10.1002/jsfa.9255.

Renard, C.M., Dupont, N., and Guillermin, P. (2007). Concentrations and characteristics of procyanidins and other phenolics in apples during fruit growth. Phytochemistry 68, 1128-1138. https://doi. org/10.1016/j.phytochem.2007.02.012.

Rop, O., Jurikova, T., Mlcek, J., Kramarova, D., and Sengee, Z. (2009). Antioxidant activity and selected nutritional values of plums (Prunus domestica L.) typical of the White Carpathian Mountains. Sci. Hortic. 122, 545-549. https://doi.org/10.1016/j.scienta.2009.06.036.

Rupasinghe, H.V., Jayasankar, S., and Lay, W. (2006). Variation in total phenolics and antioxidant capacity among European plum genotypes. Sci. Hortic. 108, 243-246. https://doi.org/10.1016/j. scienta.2006.01.020

Salvador, A., Arnal, L., Besada, C., Larrea, V., Quiles, A., and PérezMunuera, I. (2007). Physiological and structural changes during ripening and deastringency treatment of persimmon fruit cv. 'Rojo Brillante'. Postharv. Biol. Technol. 46, 181-188. https://doi. org/10.1016/j.postharvbio.2007.05.003.

Silva, B.M., Andrade, P.B., Ferreres, F., Domingues, A.L., Seabra, R.M., and Ferreira, M.A. (2002). Phenolic profile of quince fruit (Cydonia oblonga Miller) (pulp and peel). J. Agric. Food Chem. 50, 4615-4618. https://doi.org/10.1021/jf0203139.

Singleton, V.L., and Rossi, J.A. (1965). Colorimetry of total phenolics with phosphomolybdic-phosphotungstic acid reagents. Am. J. Enol. Vitic. 16, 144-158.

Sparrow, A.M., Dambergs, R.G., Bindon, K.A., Smith, P.A., and Close, D.C. (2015). Interaction of grape skin, seed, and pulp tissues on tannin and anthocyanin extraction in Pinot noir wines. Am. J. Enol. Vitic. 66, 472-481. https://doi.org/10.5344/ajev.2015.15022.

Tomás-Barberán, F.A., Gil, M.I., Cremin, P., Waterhouse, A.L., HessPierce, B., and Kader, A.A. (2001). HPLC- DAD- ESIMS analysis of phenolic compounds in nectarines, peaches, and plums. J. Agric. Food Chem. 49, 4748-4760. https://doi.org/10.1021/jf0104681.

Usenik, V., Stampar, F., and Kastelec, D. (2013). Phytochemicals in fruits of two Prunus domestica L. plum cultivars during ripening. J. Sci. Food Agric. 93, 681-692. https://doi.org/10.1002/jsfa.5783.

Usenik, V., Stampar, F., and Kastelec, D. (2014). Indicators of plum maturity: When do plums become tasty? Sci. Hortic. 167, 127-134. https://doi.org/10.1016/j.scienta.2014.01.002.

Zhang, J., Wang, X., Yu, O., Tang, J., Gu, X., Wan, X., and Fang, C. (2010). Metabolic profiling of strawberry (Fragaria $\times$ ananassa Duch.) during fruit development and maturation. J. Exp. Bot. 62, 1103-1118. https://doi.org/10.1093/jxb/erq343. 
Zurita, J., Díaz-Rubio, M.E., and Saura-Calixto, F. (2012). Improved procedure to determine non-extractable polymeric proanthocyanidins in plant foods. Int. J. Food Sci. Nutr. 63, 936-939. https://doi.or g/10.3109/09637486.2012.681634.

Received: May 29, 2019

Accepted: Oct. 18, 2019

Address of authors:

Matej Vosnjak*, Martina Persic, Robert Veberic and

Valentina Usenik

University of Ljubljana, Biotechnical Faculty, Department of

Agronomy, Chair for Fruit, Viticulture and Vegetable

Growing, Ljubljana, Slovenia

*Corresponding author; E-mail: matej.vosnjak@bf.uni-lj.si

\section{SUPPLEMENTAL INFORMATION}

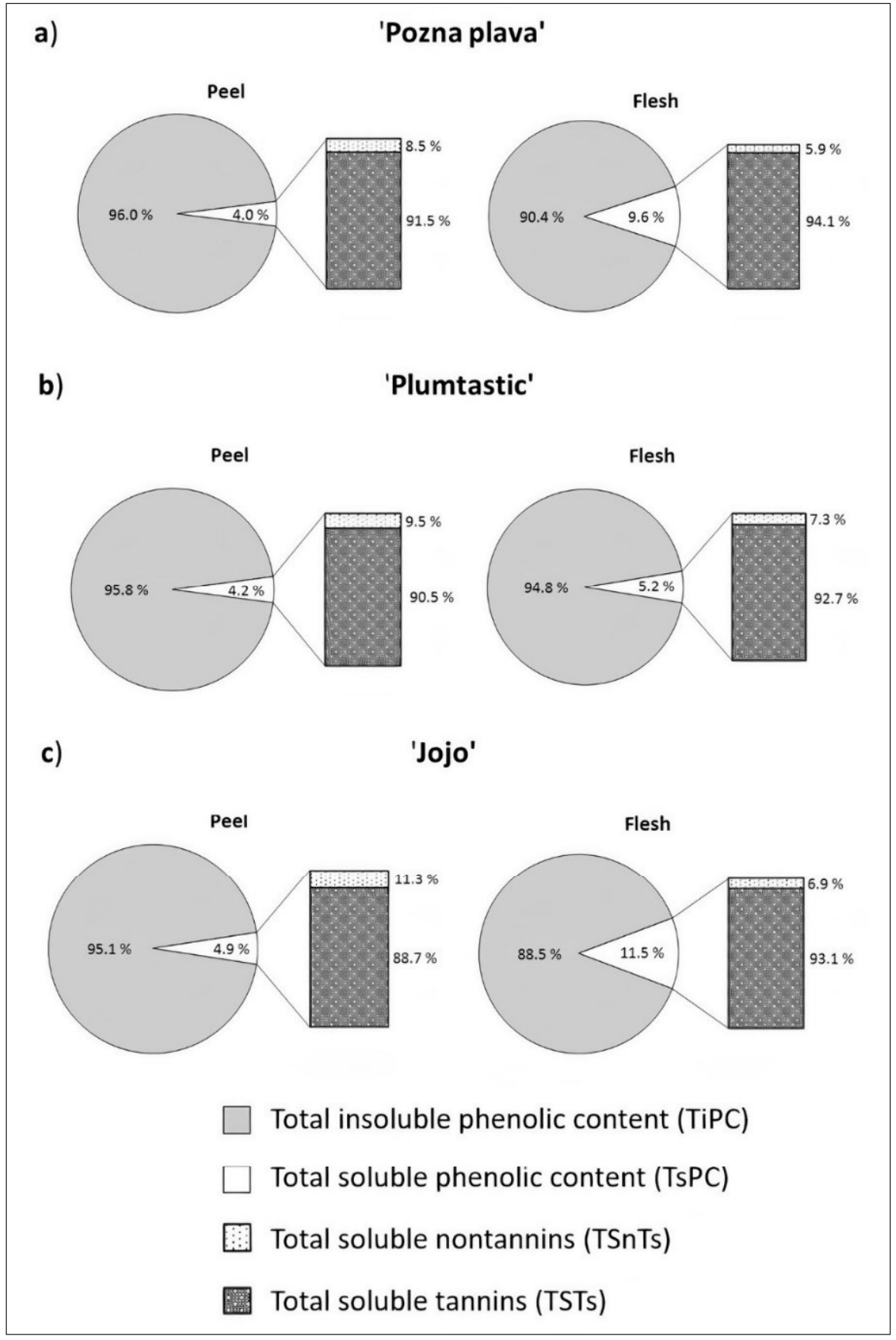

SUPPLEMENTAL INFORMATION FIGURE S1. Phenolic, tannin, and nontannin content (relative values in \%) in the peel (left) and flesh (right) of the three plum cultivars (a-c), irrespective of maturity class. 